\title{
Proksimal femur kaynamamaları
}

\section{Proximal femoral non-unions}

\author{
Ömür Çağlar, Cem Çaylı \\ Hacettepe Universitesi Tıp Fakültesi, Ortopedi ve Travmatoloji Anabilim Dalı, Ankara
}

Proksimal femur kırıkları içinde, intertrokanterik bölge kırıklarında kaynamama nadir olarak karşılaşılan bir durumdur. Bu bölgede sıklıkla, tespitte başarısızlık ve yerleştirilen implantların femur başından çıkmaları gibi komplikasyonlar karşımıza çıkar. Hastaya ait faktörler dışında ise; kırık redüksiyonu, seçilen implant ve implantın pozisyonu kaynamada önemlidir ve sonuçları etkiler. İntertrokanterik bölgeden farklı olarak; subtrokanterik bölge, daha kortikal bir yapıda, vasküler olarak fakir ve yüksek streslere maruz kalan bir kısımdır. Kaynamama bu bölgede daha sık görülür ve tedavisi zordur. Bu derlemede, femur boyun kırığı dışında kalan proksimal femur kaynamamalarında tanı ve tedavi yaklaşımları üzerinde durulacaktır.

Anahtar sözcükler: kaynamama; ıntertrokanterik kırıklar; subtrokanterik kırıklar

\begin{abstract}
Non-union in the intertrochanteric region is a rare problem among proximal femoral fractures. Complications such as failure of fixation and implant cut-out are frequent for intertrochanteric fractures. Besides, patient related factors, fracture reduction quality, the implant choice, and the position of the implant are important factors and alter the results. Unlike intertrochanteric region; subtrochanteric part has poor vascularity, and subject to high cortical stress. Therefore, non-union is more frequent and treatment is difficult in this region. In this review, diagnostic and therapeutic approaches to proximal femoral non-union will be discussed.
\end{abstract}

Key words: non-union; intertrochanteric fractures; subtrochanteric fractures
D ünyada yaşlanan nüfusun artması ile beraber, kalça kırığı sıklığının da 2030 yılında yaklaşık \%15 oranında artması beklenmektedir. Bu rakam, Amerika Birleşik Devletleri'nde yaklaşık olarak 290.000/yıl olarak hesaplanmaktadır. ${ }^{[1]}$ Intertrokanterik kırıklar, kalça kırıklarının yaklaşık yarısını (\%47), subtrokanterik kırıklar ise \%25'ini oluşturur. $^{[2]} \mathrm{Hem}$ intertrokanterik hem de subtrokanterik kırıkların tedavisi, hemen her zaman cerrahidir. Özellikle subtrokanterik uzanımı olan kırıklarda, tedavi yönetiminde yüksek kas kuwvetlerinin etkisi, normal aktivitelerde dahi oluşan yüksek aksiyel bükücü kuwetler ve kompleks kırık şekilleri tedaviyi zorlaştırır. Uzamış yaşam süresinin de getirisi olarak, kalça kırık sayısındaki artış nedeni ile tedavi başarısızlıkları ve kaynamama sıklığı da artacaktır.

İntertrokanterik bölge; femur boynunun ekstrakapsüler bölgesinden trokanter minörün alt sınırına kadar olan alanı ifade eder. Subtrokanterik bölge ise genellikle trokanter minör alt sınırından $5 \mathrm{~cm}$ distaline kadar olan mesafe olarak tanımlanır. Her ne kadar bu iki bölge birbirlerinin devamı gibi görülse de, iyileşme potansiyelleri ve revizyon seçenekleri son derece farklıdır.

Subtrokanterik kırıklar, hem daha proksimal kırıklardan hem de femur cisim kırıklarından, oluş mekanizması, tedavisi ve komplikasyonları bakımından farklıdır. Kuvvetli kas gücü kontraksiyonları ile beraber yüksek aksiyel ve makaslama kuvvetleri, tedaviyi daha da güçleştirir. Gluteus medius ve gluteus minimus kasları proksimal parçada abduksiyona neden olurken, iliopsoas proksimal parçada fleksiyon ve dış rotasyona neden olur. Adduktor kaslar ise distal parçada varus ve kısalığa neden olurlar ki bu da çoğu zaman ilk ameliyatta iyi bir redüksiyonu önler. Bu bölgede azalmış vasküler destek de, tedavide gecikmiş kaynama, kaynamama ve implant yetmezliğinde artışa neden olabilir.

Bu kırıklar genellikle, genç hastada yüksek enerjili yaralanma veya yaşlı hastada basit düşmeler sonrasında

- İletişim adresi: Doç. Dr. Ömür Çağlar, Hacettepe Universitesi Tıp Fakültesi, Ortopedi ve Travmatoloji Anabilim Dalı, 06100 Sıhhiye, Ankara Tel: 0312 - 3051209 e-posta: ocaglar@hacettepe.edu.tr

- Geliș tarihi: 1 Kasım $2017 \quad$ Kabul tarihi: 1 Kasım 2017 
karşımıza çıkar. Proksimal humerus kırıklarına benzer şekilde, femur baş, boyun, trokanter majör, minör ve cisim kırıkları pertrokanterik bölgeyi oluşturur.

\section{KLINIK DEĞERLENDIRME}

Klinik değerlendirmede, daha önce cerrahi geçirmiş ve tespit başarısızlığı olan hastalar ile patolojik hareketi olan cerrahi geçirmemiş hastalarda tanı koymak kolaydır. Bununla beraber, bazı silik kaynamama durumlarında kasık bölgesinde ağı, yürürken aksama yegane bulgular olabilir. Hastalar oturdukları yerden kalkarken veya yürümeye başlarken ağrılarının artmasından yakınırlar. Her kaynamamada olduğu gibi, iyi bir öykü ile başlanmalı, ko-morbiditeler değerlendirilmelidir. Kırık olan ve olmayan taraf karşılıklı değerlendirilmelidir. Görüntüleme olarak radyografi veya bilgisayarlı tomografi (iyileşme varlı̆̆ı ve deformitenin ayrıntılı değerlendirilmesi için) kullanılabilir. Ultrasonografi, özellikle geriatrik popülasyonda, vasküler değerlendirme açısından yararlı olabilir.

Tüm kaynamamalarda, definitif tedaviden önce enfeksiyon ekarte edilmeli veya tanısı konulup tedavi edilmelidir. Pürülan koleksiyon veya abse olmaması halinde, enfeksiyon tanısını koymak zorlaşır; laboratuvar tetkikleri, biyopsi ve kaynamama bölgesinden alınan kültürler gerekir. ${ }^{[3]}$ Beyaz küre sayısı, sedimentasyon, CRP (C-reactive protein) ve lökosit esteraz pozitifliği tanıda yardımcıdır. ${ }^{[4]}$ Intra-operative frozen ve kültürler ile bu tetkiklerin birlikte değerlendirilmesi yararlı olur.

\section{TEDAVI PLANI}

Kaynamama gelişiminde etkili faktörler, primer ve katkıda bulunan faktörler olarak ikiye ayrılabilir. Primer olanlar, mekanik instabilite, vasküler yetersizlik, kırık parçaları arasında boşluk olması ve enfeksiyon iken; etkileyici faktörler, sigara kullanımı, ilaçlar, ilerlemiş yaş, sistemik hastalıklar, venöz staz, obezite, alkol, malnütrisyon ve vitamin eksikliği olarak özetlenebilir. ${ }^{[1]}$

Bu kırıklardaki tedavi başarısı, büyük oranda başlangıçta kırığın stabilitesi ile ilişkilidir. Kaufer'in yaptığı çalışmada, kırık-implant birleşiminin stabilitesi beş faktöre bağlanmıştır: 1) kemik kalitesi, 2) kırık paterni, 3) ulaşılan redüksiyon, 4) seçilen implant ve 5) implantın yerleşimi. ${ }^{[4]}$ Bunlardan ilk iki faktörü değiştiremeyeceğimize göre, en iyi sonuç için uygun implantı seçip uygun şekilde yerleştirmeli ve bu sırada kırık parçalarının beslenmesine mümkün olduğunca az zarar vermeliyiz.

İmplant yetmezliği, pertrokanterik kırıkların yaklaşık olarak \%5'inde karşımıza çıkar ve asıl olarak altta yatan kaynamama ve redüksiyon bozukluğuna bağlıdır. Parker ve ark., kayan kalça çivilerinin sonuçlarını inceledikleri çalışmalarında, artmış femoral mediyalizasyonun ve lateral korteks defektinin, başarısızlığı yaklaşık olarak yedi kat arttırdığını bulmuşlardır. [5] İmplant stabilitesinin kaybı, çoğu zaman femur başında varus instabilitesi ve nihai olarak implantın femur başından çıkması ile sonuçlanır ki genellikle artroplasti ile tedavi edilmesi gerekir. Bu özellikle, tipapeks mesafesinin iyi olmadığı ve lag vidasının merkez-merkez yerleşimi olmayan hastalarda karşımıza çıkar (Şekil 1).

Cerrahi öncesi değerlendirme sonrası temel olarak, tedavide iki yöntem mevcuttur: tespitin revizyonu ya da artroplasti. Bu yöntemler arasında seçim yapılacağı zaman dikkat edilmesi gereken bazı önemli noktalar;

- proksimal femurdaki kemik stoğu,

- enfeksiyon varlığı,

- hastanın fonksiyon seviyesi ve yaşam beklentisi (genç hastalarda mümkün olduğunca femur başı korunmalıdır) ve

- kalça eklem kıkırdağının etkilenmesi ve osteoartrit varlı̆̆ıdır.

Tedavide artroplasti ile revizyon arasında karar verirken en önemli iki faktör, proksimal femur kemik stoğu ve kalça ekleminin yeterliliğidir. İmplantın ekleme migrasyonu ile kalça hareketleri ile ilişkili problemler oluşmuşsa, artroplasti uygun bir seçenek olacaktır. ${ }^{[6]}$ Genellikle bu hastalarda standart kesi seviyesinin altında kemik kaybı mevcut olduğundan, kalkar destekli protezler düşünülebilir. ${ }^{[7]}$ Uzun femoral stemler kullanılırken, önceki tespitteki vida deliklerinden iki korteks çapı kadar uzağa devam edecek şekilde, femoral stem tercih etmek akılcı olabilir. ${ }^{[8]}$ Trokanter majör kaynakI problemlerin yönetimi de problemlere neden olur; trokanter majörün kaynamama veya yanlış kaynaması durumunda trokanterik kaydırma yapılması ile femoral kanal hazırlanması için uygun ortam hazırlanabilir; böylece aynı zamanda, vastus lateralis ve abduktor kaslar da korunmuş olur. ${ }^{[9]}$ Ayrıca, revizyon veya artroplasti için yeterli kemik stoğu yoksa, tümör tipi mega-protezler seçilebilir. ${ }^{[10]}$

Genç ve fonksiyonel hastada, kemik stoğunu koruyup tespit revizyonu ile kaynama sağlamak için çaba gösterilmelidir. Özellikle proksimal kemik stoğu iyi olan genç hastalarda, sabit açılı implantlar femur başının inferiorunu hedefleyecek şekilde kullanılabilir. Bu bölge çoğu zaman ilk tespit sırasında hasar görmemiştir. ${ }^{[7]}$ Vries ve ark. ${ }^{[11]}, 33$ kalçanın 32'sinde AO-ASIF $95^{\circ}$ kamalı plak ile kaynamama tedavisinde başarıya ulaşmışlardır. 


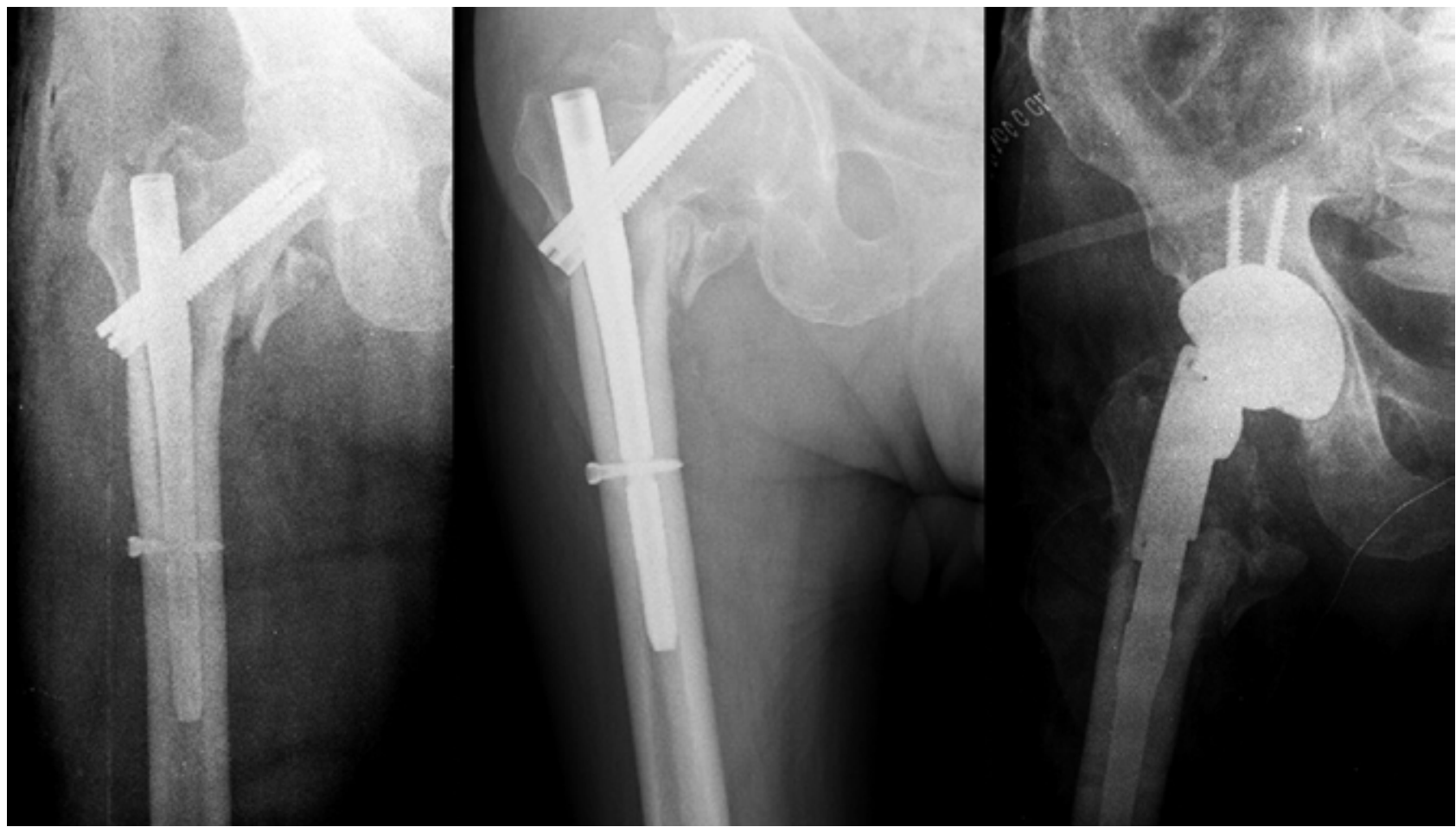

Şekil 1. Yetmiş iki yaşında erkek hasta; instabil intertrokanterik kırık yeni nesil sefalomedüller çivi ile tespit edilmiş. Kırığın varus malredüksiyonuna; lag vidasının baş içerisinde yerleşimine ve tip-apeks uzunluğuna dikkat ediniz. Zaman içinde kırıkta varus çökmesi ve cut-out gelişmesi üzerine, distalden tespit sağlayan bir protez ile tespit revizyonu.

Kırık parçalarının arasındaki boşluğun azaltılması ve kompresyon teknikleri veya greft ile kapatılması gereklidir. Stabilitenin arttırılması, biyolojik ve vasküler açıdan şartların iyileştirilmesi amaçlanmalıdır. ${ }^{[10]}$ Giannoudis ve ark., implant kırığı ve atrofik, aseptik subtrokanterik kaynamaması olan 14 hastanın tedavi sonuçlarını rapor ettikleri yazılarında, kaynamamanın ilk belirtisi olarak distal kilit vidalarında kırılmanın olduğunu; bunu izleyen dönemde ise proksimal kesimde implant kırığı oluşacağını belirtmişlerdir. Yine, subtrokanterik kırık tespitinde varus yanlış diziliminden kaçınmak gerektiğini belirtmişlerdir. Ortalama $5^{\circ}$ üzeri varusu, risk faktörü olarak tanımlamışlardır. Tedavide ise, hem mekanik hem de biyolojik tedavinin birlikte olduğu "elmas" konsepti ile yüksek oranda başarı elde etmişlerdir. ${ }^{[12]}$ Bu konsepte, $95^{\circ}$ kamalı plak ile beraber; oymadan elde ettikleri greftler, BMP (bone morphogenetic protein) ve iliak kanattan elde edilmiş olan kemik iliği aspiratını biyolojik destek olarak kullanmışlardır (Şekil 2 ve Şekil 3).

Rollo ve ark., 35 hastayı değerlendirdikleri serilerinde, 22 hastaya yalnızca lateral kamalı plak ve 13 hastaya hem kamalı plak hem de mediyalden yapısal allogreft desteği uygulamışlardır. Allogreft desteği uygulanan grupta önemli bir komplikasyonları yok iken, diğer grupta dört adet implant kırılması yaşamışlardır. Yazarlar, zor revizyon hastalarında mediyal desteklemenin önemini anlatmışlardır. ${ }^{[13]}$

Proksimal femur kaynamamalarında bir başka tartışma da; önceki iyi poziyonda olan tespitin bırakılıp ek destek yapılmasının mı; yoksa çivinin tamamen değiştirilmesinin mi gerekli olduğudur. Kang ve ark., bu konuda yaptıkları çalışmada 19 hastayı incelemişlerdir. Tüm hastalara greftleme yapmalarına karşın, implantın tamamen çıkarıldığı grupta mevcut fibrotik non-union dokusu daha iyi temizlendiği için sonuçların daha iyi olduğunu bulmuşlardır (Şekil 4). ${ }^{[14]}$

Eşlik eden enfeksiyon varlığı, tedavi şeklinden bağımsız olarak, kaynamamada tedaviyi zorlaştırır. Enfeksiyon tedavisinde, evrelendirilerek cerrahi yapılması düşünülmelidir. Cerrahi olarak revizyon planlandığında; kaynamama bölgesinin debridmanı, cansız yumuşak dokunun çıkarılması ve kırık bölgesinin tespiti ilk basamak olmalı; buna ek olarak olası kemik defektlerinin giderilmesi de plana dahil olmalıdır.

Enfeksiyon varlığında artroplasti tercihinde de iki basamaklı tedavi gereklidir: ilk aşamada implantın 


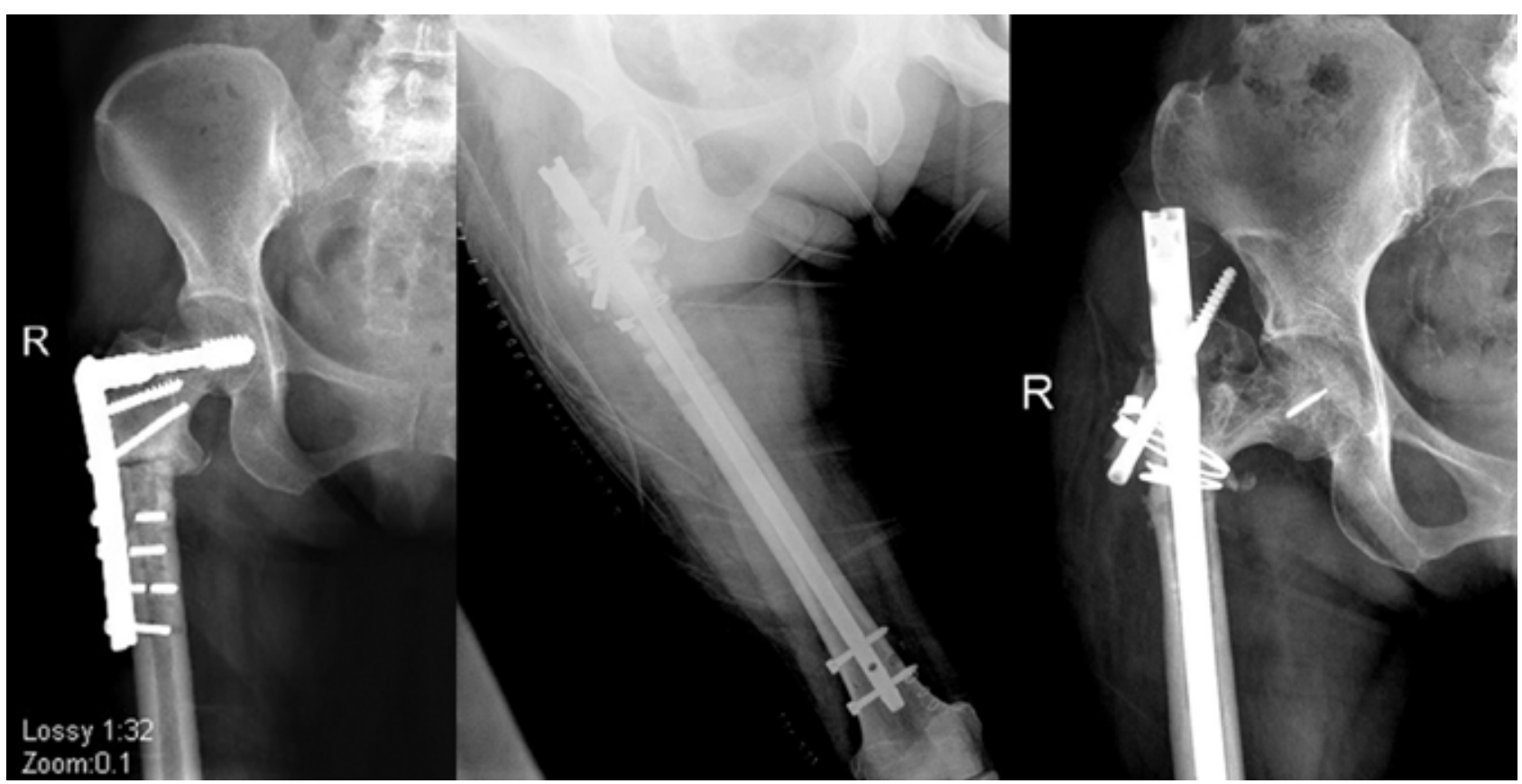

Şekil 2. Altmış yaşında bayan hasta; opere subtrokanterik kırık. Kırık distalindeki tüm vidaların kırık olduğuna dikkat ediniz. Varus yanlış dizilimini de göz ardı etmeyin. Hastanın uzun sefalomedüller çivi ile tespiti sonrasında da femur başı yeterince tespit edilmemiş.

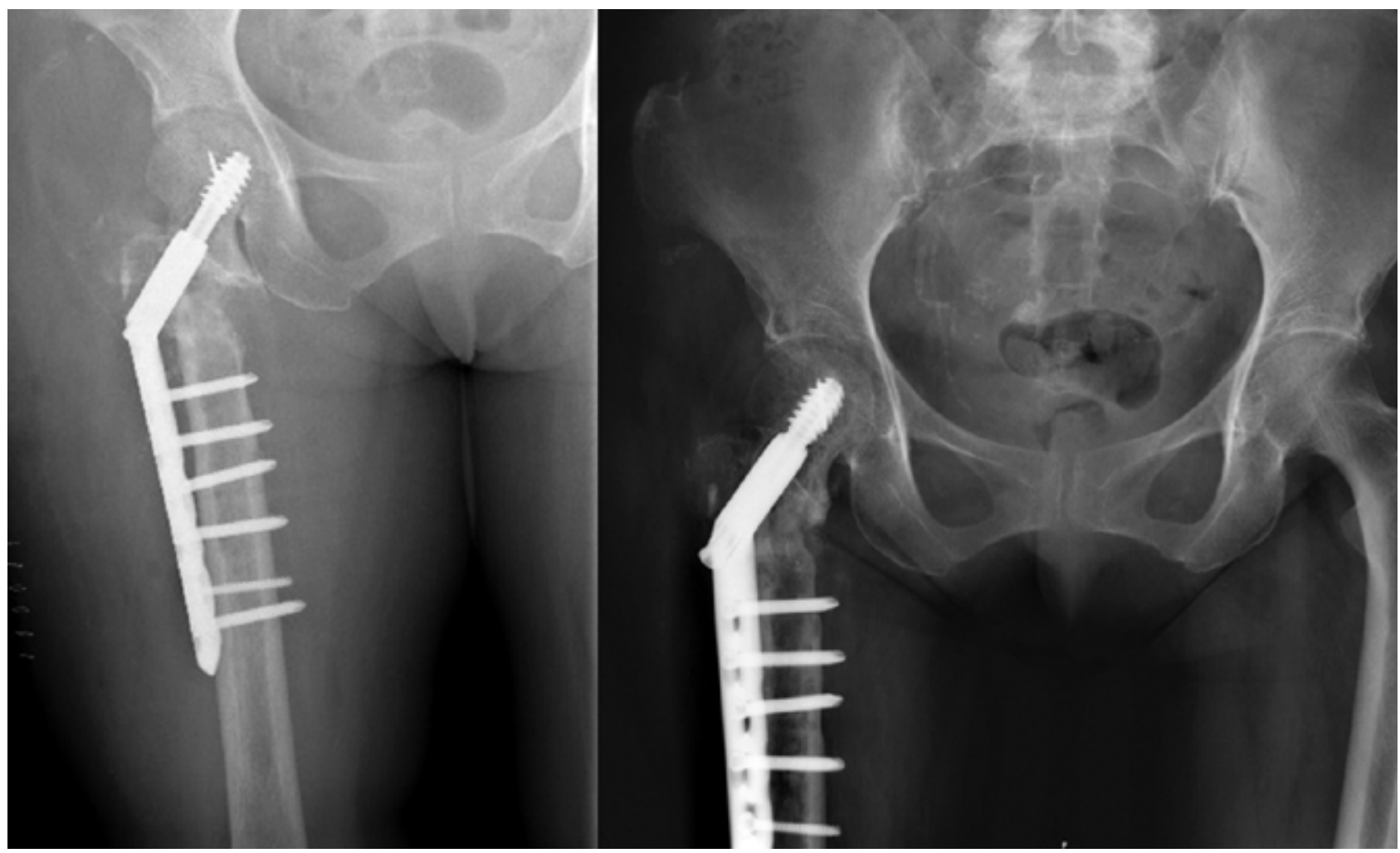

Şekil 3. Aynı hastanın tedavisinde proksimal femura valgus osteotomisi ve iliak kanattan alınan greft ile mediyal destekleme yapıldıktan beş yıl sonra hastanın kırığının kaynamış hali. 


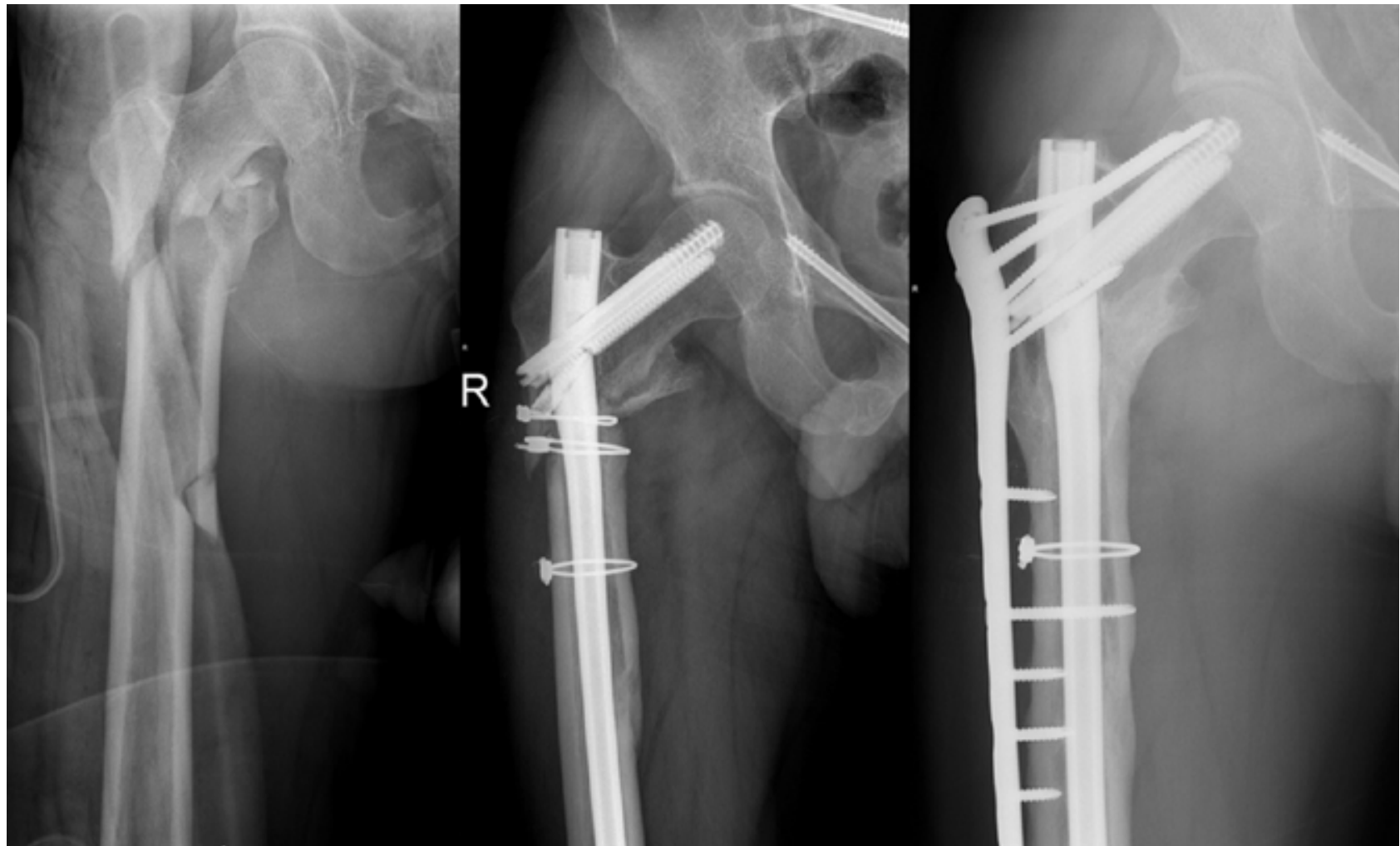

Şekil 4. Yirmi yedi yaşında erkek hasta; trafik kazası sonrası çok parçalı subtrokanterik femur kırığı nedeniyle sefalomedüller çivileme yapılmış. Ameliyat sonrasında 2. yılda kaynamama ve mevcut implantta kırılma gözleniyor. Hastanın çivisi yerinde bırakılarak anatomik proksimal femur plağı ile desteklenen tespitten bir yıl sonra kırığın kaynadığı görülüyor.

çıkarılması, cansız kemiğin debride edilmesi, derin kültür ve doku biyopsisi alınması gelir; sonrasında, fonksiyonel antibiyotikli kalça protezi yerleştirilir ve bakteri spesifik antibiyoterapi yapılır. Enfeksiyonun geçtiğini düşündüren seroloji ve kültür sonuçları sonrası, definitif artroplasti cerrahisi yapılabilir.

\section{SONUÇ}

Sonuç olarak; proksimal femur kırıklarında kaynamama nadir, fakat tedavisi zor olan bir komplikasyondur. Tedavi planlamasında, hem biyoloji hem de mekanik dikkate alınmalıdır. Kalça ekleminin etkilendiği yaşlı hastalarda artroplasti bir seçenek olabililirse de, kemik stoğunun yeterli olduğu hastalarda kaynama elde etmeye çalışılmalıdır. Daha önceden çivilenmiş ancak dizilimi uygun ve varusu olmayan hastalarda, daha geniş bir çivi ile değişim yapılabilir. Dizilim bozukluğu var ise; kırık hattının debridmanı, dizilim bozukluğunun düzeltilmesi ve tespit amaçlanmalıdır. Literatürde, uygun tedavi ile başarı sonuçlarının yüksek olduğu bildirilmektedir.

\section{KAYNAKLAR}

1. Dziadosz D. Considerations with failed intertrochanteric and subtrochanteric femur fractures: how to treat, revise, and replace. J Orthop Trauma 2015;29 Suppl 4:S17-21. Crossref

2. Stevens JA, Rudd RA. The impact of decreasing U.S. hip fracture rates on future hip fracture estimates. Osteoporos Int 2013;24(10):2725-8. Crossref

3. Liu JZ, Saleh A, Klika AK, Barsoum WK, Higuera CA. Serum inflammatory markers for periprosthetic knee infection in obese versus non-obese patients. J Arthroplasty 2014;29(10):1880-3. Crossref

4. Kaufer $\mathrm{H}$. Mechanics of the treatment of hip injuries. Clin Orthop Relat Res 1980;(146):53-61.

5. Parker MJ. Trochanteric hip fractures. Fixation failure commoner with femoral medialization, a comparison of 101 cases. Acta Orthop Scand 1996;67(4):329-32.

6. Weiss RJ, Karrholm J, Hailer NP, Beckman MO, Stark A. Salvage of failed trochanteric and subtrochanteric fractures using a distally fixed, modular, uncemented hip revision stem. Acta Orthop 2012;83(5):488-92. Crossref

7. Haidukewych GJ, Berry DJ. Salvage of failed treatment of hip fractures. J Am Acad Orthop Surg 2005;13(2):101-9.

8. Patterson BM, Salvati EA, Huo MH. Total hip arthroplasty for complications of intertrochanteric fracture. A technical note. J Bone Joint Surg Am 1990;72(5):776-7. 
9. Haidukewych GJ, Berry DJ. Hip arthroplasty for salvage of failed treatment of intertrochanteric hip fractures. J Bone Joint Surg Am 2003;85-A(5):899-904.

10. Parvizi J, Tarity TD, Slenker N, Wade F, Trappler R, Hozack WJ, Sim FH. Proximal femoral replacement in patients with non-neoplastic conditions. J Bone Joint Surg Am 2007;89(5):1036-43. Crossref

11. de Vries JS, Kloen P, Borens O, Marti RK, Helfet DL. Treatment of subtrochanteric nonunions. Injury 2006;37(2):203-11. Crossref

12. Giannoudis PV, Ahmad MA, Mineo GV, Tosounidis TI, Calori GM, Kanakaris NK. Subtrochanteric fracture non-unions with implant failure managed with the "Diamond" concept. Injury 2013;44 Suppl 1:S76-81. Crossref
13. Rollo G, Tartaglia N, Falzarano G, Pichierri P, Stasi A, Medici A, Meccariello L. The challenge of non-union in subtrochanteric fractures with breakage of intramedullary nail: evaluation of outcomes in surgery revision with angled blade plate and allograft bone strut. Eur J Trauma Emerg Surg 2017;43(6):853-61. Crossref

14. Kang SH, Han SK, Kim YS, Kim MJ. Treatment of subtrochanteric nonunion of the femur: whether to leave or to exchange the previous hardware. Acta Orthop Traumatol Turc 2013;47(2):91-5. 